\title{
Patterned films by atomic layer deposition using Parafilm as a mask
}

\section{Zhang, Chao}

2018-01

Zhang , C , Kalliomäki , J , Leskelä , M \& Ritala , M 2018 , ' Patterned films by atomic layer deposition using Parafilm as a mask ' , Journal of vacuum science \& technology : an official journal of the American Vacuum Society , vol. 36 , no. 1 , ARTN 01B102 . https://doi.org/10.1116/1.5001033

http://hdl.handle.net/10138/322037

https://doi.org/10.1116/1.5001033

acceptedVersion

Downloaded from Helda, University of Helsinki institutional repository.

This is an electronic reprint of the original article.

This reprint may differ from the original in pagination and typographic detail.

Please cite the original version. 


\title{
Patterned films by atomic layer deposition using Parafilm as a mask
}

\author{
Chao Zhang, Jesse Kalliomäki, Markku Leskelä, Mikko Ritala ${ }^{\text {a) }}$ \\ Department of Chemistry, University of Helsinki, P.O. Box 55, Fl-00014 Helsinki, Finland \\ a) Electronic mail: Mikko.Ritala@helsinki.fi
}

This paper presents a new method for depositing patterned films by atomic layer deposition (ALD) using Parafilm as a mask to block the film growth on selected areas of the substrate surface. This offers an easy and efficient method for large area patterning from the millimeter to even meter scale as needed, for example, for protecting contact areas in integrated circuits and microelectromechanical system devices and in preventing film growth on the backside of substrates. It is shown here that Parafilm can protect the substrate against $\mathrm{Al}_{2} \mathrm{O}_{3}, \mathrm{TiO}_{2}$, and Ir film growth effectively. However, outgassing from the Parafilm affects the film growth on the unmasked areas differently for the three materials. For $\mathrm{Al}_{2} \mathrm{O}_{3}$, there are no significant effects on the growth rate and film quality on the nonmasked areas and the thickness profiles next to the Parafilm masked areas are narrow. For $\mathrm{TiO}_{2}$ and Ir, by contrast, the thickness profiles are wider and outgassing also slows down the Ir growth. Energy dispersive X-ray analysis confirms that Ir does not grow on Parafilm. $\mathrm{Al}_{2} \mathrm{O}_{3}$ and $\mathrm{TiO}_{2}$ films do grow on Parafilm, but after the ALD process, the Parafilm can be peeled off easily with tweezers and the areas under the Parafilm mask are without any deposition. 


\section{INTRODUCTION}

Atomic layer deposition (ALD) is a thin film deposition technique that has become increasingly important in many areas, especially in microelectronics ${ }^{1}$. ALD is a self-limiting film growth technique, typically relying on two half cycles of surface reactions achieved by alternately supplying two gaseous precursors onto substrate surfaces. This growth mechanism provides ALD many advantageous characteristics compared to the chemical vapor deposition (CVD) technique, such as excellent conformality, large area uniformity, and accurate film thickness control down to the atomic level ${ }^{2,3}$. ALD films usually grow uniformly like a "blanket", i.e., the films grow on all the substrate surfaces exposed to the precursor vapors. However, for many applications the films are needed only on designated surface areas. For example, there are many patterned structures in metal oxide semiconductor field effect transistors (MOSFETs) which are critical components in integrated circuits (ICs) ${ }^{4,5}$. In ALD processes the film growth depends on surface reactions between the gaseous precursors and reactive sites, predominantly hydroxyl $(\mathrm{OH})$ groups, existing on substrate surface. Therefore, it has been possible to achieve patterned ALD film growth by modifying the surface properties ${ }^{6-9}$.

Selective-area ALD is a bottom-up approach enabling deposition of thin films only on the desired surface areas, thereby accomplishing film patterning more easily as compared with the conventional lithography methods. Selective-area ALD has already been studied for several years, with most of the studies focusing on using self-assembled monolayers (SAMs) as resist layers to block the reactive sites, typically $-\mathrm{OH}$, on $\mathrm{Si}^{10,11}$. The surface areas with the patterned $\mathrm{SAMs}$ are terminated with $-\mathrm{CH}_{3}$ groups that have been proved to be effective in inhibiting most of the ALD film nucleation ${ }^{12}$, and consequently, there is film growth only on the areas without SAMs. To date, SAMs have been used for preventing growth of many ALD films, such as $\mathrm{HfO}_{2}{ }^{10,13,14}, \mathrm{Al}_{2} \mathrm{O}_{3}{ }^{15}, \mathrm{TiO}_{2}{ }^{16,17}, \mathrm{Ru}^{18}, \mathrm{PbS}^{19}, \mathrm{Pt}^{10}$ and $\mathrm{ZnO}^{20}$. Another 
method to attain selective-area ALD is to use thermally stable and unreactive polymers as growthpreventing mask layers. The benefits of this method are that polymer layers are easy and fast to prepare by spin-coating and can be patterned by photolithography. Moreover, the polymers are simple to remove from the surface areas after the ALD process. Poly (methyl methacrylate) (PMMA) and poly (vinyl pyrrolidone) (PVP) have been reported to be effective in blocking $\mathrm{ALD}$ growth of $\mathrm{TiO}_{2}, \mathrm{Al}_{2} \mathrm{O}_{3}, \mathrm{ZrO}_{2}, \mathrm{Ir}$, $\mathrm{Pt}$, and $\mathrm{Ru}^{21-25}$. In some of these cases, ALD films do grow on the polymer but the polymers still protect the substrate surface from the ALD deposition and allow patterning by lift-off.

So far, almost all the studies on selective-area ALD have concentrated on methods capable of micro- and even nanoscale patterning, due to the increasing demands for new nanofabrication and nanopatterning techniques in IC. Patterned deposition on a larger area scale is also sometimes needed, for example, in preventing film growth on the backside of substrates, which is a common and hard to avoid problem in ALD processes. Film growth on contact areas in IC and MEMS devices must also be avoided because $\mathrm{Al}_{2} \mathrm{O}_{3}$ and other insulator films would have undesirable effects on the electric contacts. Langston et al. reported an approach for preventing ALD film growth over large surface areas by utilizing polished silicon wafer pieces as masks pressed with springs against Si substrates. Some film growth was evident under the masks, however, attributed to precursor vapor diffusion ${ }^{26}$. This method is inexpensive, clean, and viable for dynamic masking, but the necessary assemblies of silicon masks are complicated and may not be feasible in all types of ALD reactors - particularly in those with limited space in the reaction chamber.

In this article, we provide an easy and efficient way to achieve patterned ALD films by using Parafilm as a mask layer to protect the substrate against the ALD film growth. Parafilm is a thermoplastic paraffin film which is applicable on complex shapes due to its high ductility. It has a low melting point of $60{ }^{\circ} \mathrm{C}$, but we observed that the resulting liquid is so viscous that it does not spread or even flow on a vertical substrate until high temperature. Parafilm adheres on the substrate surface on its own, and so, no 
adhesive is needed unlike, for example, in Kapton tape. Parafilm is therefore much easier to remove after an ALD process with only tiny amounts of residue left which can be washed away with ethanol. The substrate protection capability of Parafilm is demonstrated by using the ALD processes of $\mathrm{Al}_{2} \mathrm{O}_{3}, \mathrm{TiO}_{2}$, and Ir and characterized by energy-dispersive X-ray spectroscopy (EDX), reflectance spectrometer, optical microscope and time-of-flight elastic recoil detection analysis (ToF-ERDA).

\section{EXPERIMENT}

Parafilm (BEMIS) was cut to square pieces with a size of $1 \times 1 \mathrm{~cm}$, then pressed onto (100) silicon substrate $(5 \times 5 \mathrm{~cm})$ as tightly as possible by hand to remove air from the areas beneath the Parafilm mask. After the preparation, the samples were baked first on a hot plate at $60{ }^{\circ} \mathrm{C}$ for 10 min and then in an oven at $200^{\circ} \mathrm{C}$ for $2 \mathrm{~h}$ under nitrogen flow to reduce the volatile substances released from the Parafilm. After the ALD process, the Parafilm mask could be peeled off easily with tweezers, and any remaining residue from the Parafilm could be removed by sonication in ethanol for $10 \mathrm{~min}$. If in some applications the solvent cleaning is not acceptable, it can be replaced by other methods, like oxygen plasma cleaning.

The patterned samples were tested using several ALD processes. $\mathrm{Al}_{2} \mathrm{O}_{3}$ was deposited from trimethylaluminum (TMA) and $\mathrm{H}_{2} \mathrm{O}$ for 1000 cycles at different temperatures up to $300{ }^{\circ} \mathrm{C}$. For $\mathrm{TiO}_{2}$ deposition, $\mathrm{TiCl}_{4}$ and $\mathrm{H}_{2} \mathrm{O}$ were used as precursors in depositions carried out at 100 and $175{ }^{\circ} \mathrm{C}$. Iridium was deposited with $\operatorname{Ir}(\mathrm{acac})_{3}\left(\mathrm{acac}=2\right.$, 4-pentanedione) and $\mathrm{O}_{2}$ as precursors for 1000 cycles at $225^{\circ} \mathrm{C}$ 27. The films were deposited in an F120 reactor (ASM Microchemistry, Ltd., Finland) and a SUNALE ALD reactor (Picosun Oy, Finland). Nitrogen was used as carrier and purging gas. The pressure inside the reactor chamber was about 10 mbar during the ALD processes.

The patterned ALD films were studied using a Hitachi S-4800 field-emission-scanning electron microscope equipped with an INCA 350 energy dispersive X-ray spectrometer to determine whether 
there were films grown under the Parafilm mask. The thicknesses of the films grown on the Parafilm and on the unmasked Si were calculated from the EDX data using a GMRFILM program ${ }^{28}$ with bulk densities for $\mathrm{Al}_{2} \mathrm{O}_{3}$ and Ir. Film thicknesses were also measured using a Nanospec $®$ AFT model 4000 reflectance spectrometer. The chemical composition of the ALD films was studied by ToF-ERDA.

\section{RESULTS AND DISCUSSION}

A Parafilm patterned substrate was prepared by pressing the Parafilm piece $($ size: $1 \times 1 \mathrm{~cm})$ tightly onto the silicon substrate to remove air gases underneath the Parafilm mask. This is important for avoiding air bubbles and fracture of the Parafilm during baking and annealing steps. The Parafilm patterned Si substrate was heated gently on a hot plate at $60{ }^{\circ} \mathrm{C}$ for $10 \mathrm{~min}$ to ensure a tight contact of the Parafilm with $\mathrm{Si}$, thereby eliminating ALD film growth under the mask through diffusion of ALD precursors into the protected areas from the edges of the Parafilm mask. Annealing can also reduce outgassing from Parafilm which can disturb the film growth, as will be discussed below.

As noted in the last paragraph of Sec. I, despite the low melting point $\left(60^{\circ} \mathrm{C}\right)$ of Parafilm, it still can be used at relatively high temperatures as a mask for protecting Si substrates against the ALD film growth. However, the change of the shape and size of Parafilm at high ALD deposition temperatures needs to be considered. The Parafilm patterned Si substrates were annealed for $6 \mathrm{~h}$ in an ALD reactor under a $\mathrm{N}_{2}$ atmosphere at different temperatures up to $300{ }^{\circ} \mathrm{C}$ to check the stability of the Parafilm at these temperatures. The samples were held horizontally in the SUNALE ALD reactor chamber with a pressure of about 10 mbar. It was observed that these Parafilm pieces retained their shapes very well even after annealing at $300{ }^{\circ} \mathrm{C}$ with only a little shrinkage in one direction from 1.0 to $0.9 \mathrm{~cm}$ (Fig. 1). According to this result, Parafilm can be considered as a mask layer for preventing ALD film growth at temperatures up to $300{ }^{\circ} \mathrm{C}$. 


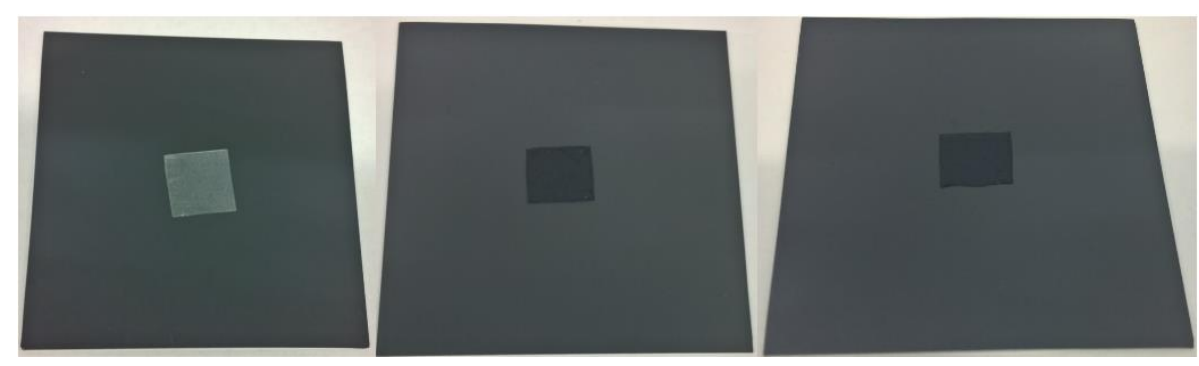

FIG. 1. (Color online) Parafilm $(1 \times 1 \mathrm{~cm})$ patterned Si substrates $(5 \times 5 \mathrm{~cm})$.

The capability of Parafilm to protect the substrate against the $\mathrm{Al}_{2} \mathrm{O}_{3}$ ALD process using TMA and water as precursors was tested in the SUNALE ALD reactor with a horizontal substrate holder. The deposition temperature was varied from 175 to $300^{\circ} \mathrm{C}$ with an interval of $25^{\circ} \mathrm{C}$. At these temperatures, the Parafilm protects the surface against the $\mathrm{Al}_{2} \mathrm{O}_{3}$ growth effectively without significant effects on the film growth on the nonmasked areas. Fig. 2(a) shows photographs of six patterned $\mathrm{Al}_{2} \mathrm{O}_{3}$ films deposited at different temperatures. EDX analysis [Figure 2(b)] verifies that there is no $\mathrm{Al}_{2} \mathrm{O}_{3}$ film growth on those areas of $\mathrm{Si}$ substrate that was under the Parafilm mask. By contrast, $\mathrm{Al}_{2} \mathrm{O}_{3}$ films were detected on top of the Parafilm mask, with a film thickness $90 \mathrm{~nm}-$ close to the thickness of $\mathrm{Al}_{2} \mathrm{O}_{3}$ on $\mathrm{Si}$. Anyhow, after the $\mathrm{Al}_{2} \mathrm{O}_{3}$ film growth, the Parafilm is still easy to peel off, and the patterning method thus works as a liftoff process. While the patterning is otherwise successful, the interference colors next to the edge of the Parafilm patterned areas, over a distance of about $1 \mathrm{~mm}$, indicate that in these areas the films are thinner and non-uniform. Reflectance spectrometer measurements confirm the thickness profile in the sample deposited at $175^{\circ} \mathrm{C}$ [Fig. 2(c)]. Outside the $1 \mathrm{~mm}$ wide profile areas, the films are uniform with the thickness of $\sim 95 \mathrm{~nm}$. The growth rate is $1.0 \AA$ A/cycle at $175^{\circ} \mathrm{C}$, consistent with the literature ${ }^{29}$. In the patterned $\mathrm{Al}_{2} \mathrm{O}_{3}$ films grown at higher temperatures, the thickness profiles are similar as in the sample deposited at $175^{\circ} \mathrm{C}$. The reason for the film being thinner next to the Parafilm protected area is assumed to be that volatile substances released from the Parafilm at the high deposition temperatures slightly inhibit the $\mathrm{Al}_{2} \mathrm{O}_{3}$ film growth. Parafilm consists primarily of polyolefins and paraffin waxes, and so, the 
volatile substances should be mixtures of small hydrocarbon compounds. Patterned $\mathrm{Al}_{2} \mathrm{O}_{3}$ depositions were also carried out in a F120 ALD reactor. In this flow-type reactor, the substrates were held vertically, as opposed to the horizontal substrate position employed in the SUNALE ALD reactor. We found that on the vertical substrates, the Parafilm works well up to $275^{\circ} \mathrm{C}$ but starts to flow downward at $300{ }^{\circ} \mathrm{C}$ [Fig. 2(d)].

a) In SUNALE ALD reactor

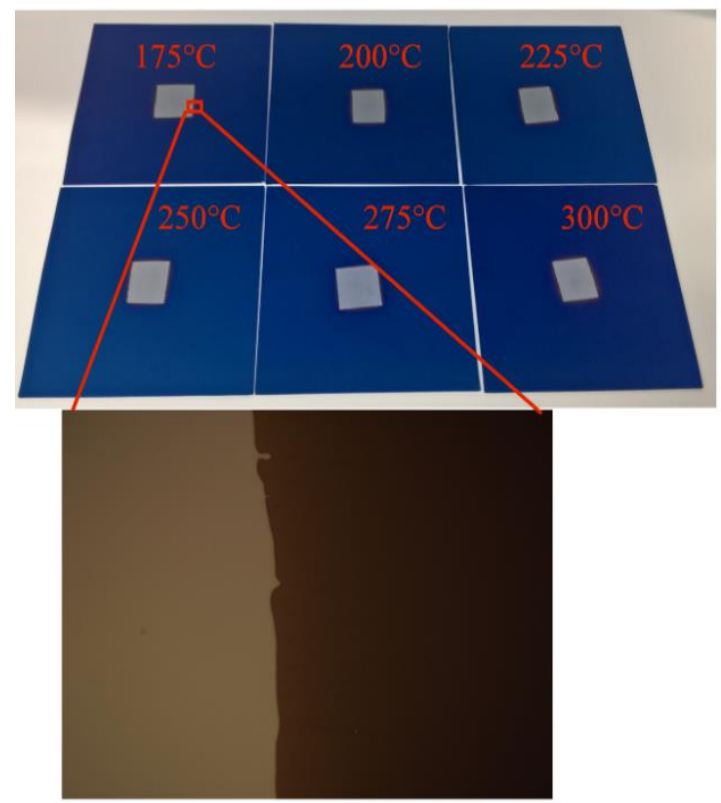

d) In F120 ALD reactor b)

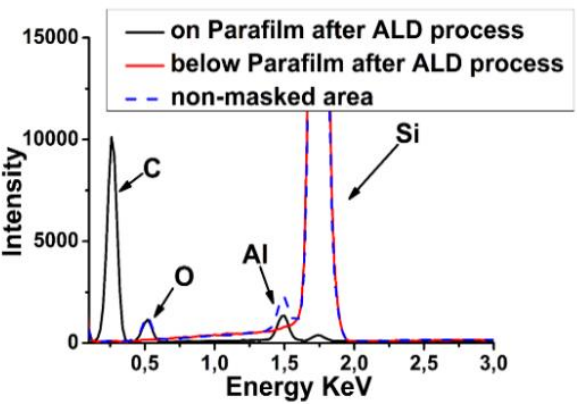

c)

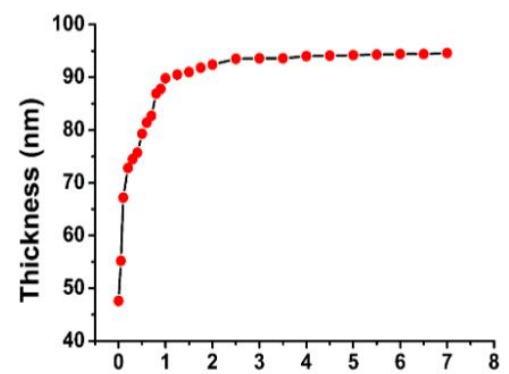

Distance from the edge of patterned area $(\mathrm{mm})$

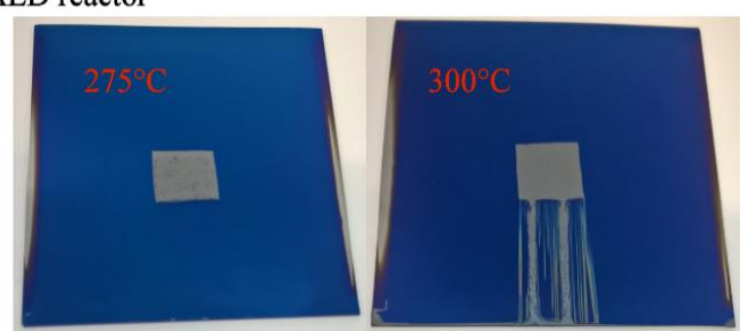

FIG. 2. (Color online) (a) Photographs of six $5 \times 5 \mathrm{~cm}$ substrates with patterned $\mathrm{Al}_{2} \mathrm{O}_{3}$ films deposited from TMA and $\mathrm{H}_{2} \mathrm{O}$ at different temperatures from 175 to $300{ }^{\circ} \mathrm{C}$, after the Parafilm removal. The image at the bottom is taken using an optical microscope with a magnification of $20 \times$ at the edge of the Parafilm protected areas. (b) EDX measurements on the Parafilm, below the Parafilm and on the nonmasked areas after the $\mathrm{Al}_{2} \mathrm{O}_{3} \mathrm{ALD}$ processes. (c) Film thickness as a function of the distance from the edge of the Parafilm protected areas in the sample deposited at $175^{\circ} \mathrm{C}$. (d) Photographs of two patterned $\mathrm{Al}_{2} \mathrm{O}_{3}$ films deposited from TMA and $\mathrm{H}_{2} \mathrm{O}$ at 275 and $300{ }^{\circ} \mathrm{C}$ in the F120 ALD reactor, before the Parafilm removal.

$\mathrm{TiO}_{2}$ was deposited at 100 and $175^{\circ} \mathrm{C}$ [Fig. 3(a)] on the Parafilm masked samples. The EDX measurement [Fig. 3(b)] confirms that there is no $\mathrm{TiO}_{2}$ growth below the Parafilm mask. $\mathrm{TiO}_{2}$ films were 
deposited on the Parafilm, so also in this case, the patterning method works as a lift-off process. In the $\mathrm{TiO}_{2}$ process at $175^{\circ} \mathrm{C}$, however, the nonuniform area at the edge of the Parafilm protected areas became wider, $5 \mathrm{~mm}$ [Fig. 3(c)], than that in the $\mathrm{Al}_{2} \mathrm{O}_{3}$ process, $1 \mathrm{~mm}$ [Fig. 2(c)]. This may be explained by that the ALD chemistry of $\mathrm{Al}_{2} \mathrm{O}_{3}$ is more robust than that of the $\mathrm{TiO}_{2}$ process, and therefore, outgassing of Parafilm has stronger effects on the $\mathrm{TiO}_{2}$ process. Outside the profile areas $(5 \mathrm{~mm}), \mathrm{TiO}_{2}$ films were uniform with a thickness of $\sim 41 \mathrm{~nm}$ as measured using a reflectance spectrometer. To reduce the outgassing effects, several methods were tried: prolonging the annealing time before the ALD process starts, increasing purge time from 5 to $30 \mathrm{~s}$, and lowering the deposition temperature from 175 to $100{ }^{\circ} \mathrm{C}$. Nevertheless, none of these methods noticeably reduced the outgassing effects, but rather made the situation even worse. It appears that at lower deposition temperature $\left(100^{\circ} \mathrm{C}\right)$, the chemistry of the process is not as effective as that at higher temperature $\left(175^{\circ} \mathrm{C}\right)$ and can be disturbed more easily by the outgassing from the Parafilm. Also, at low temperatures, the outgassed molecules may adsorb stronger on the growth areas. 
a)

Before the Parafilm removal

After the Parafilm removal

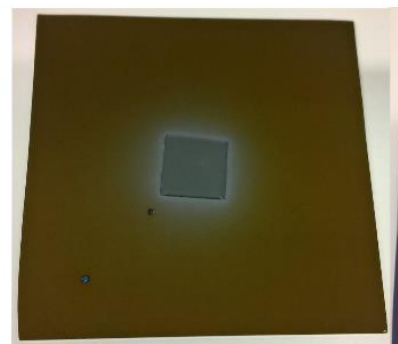

$100^{\circ} \mathrm{C} / 5 \mathrm{~s} \mathrm{~N} 2$ purge
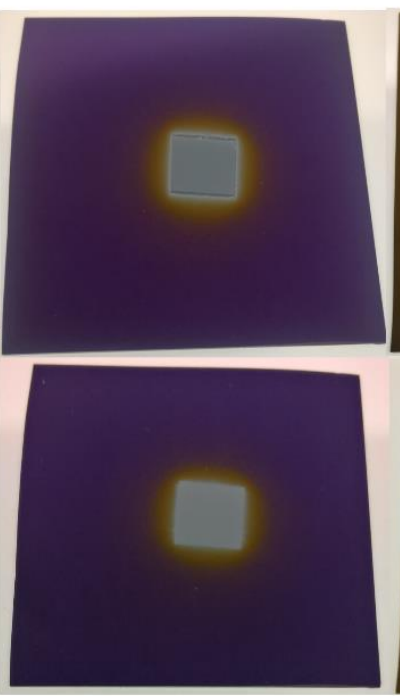

c)

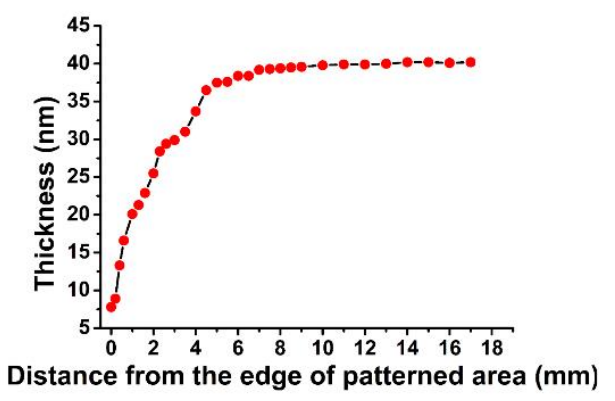

FIG. 3. (Color online) (a) Photographs of three $5 \times 5 \mathrm{~cm}$ substrates with patterned $\mathrm{TiO}_{2}$ films deposited from $\mathrm{TiCl}_{4}$ and $\mathrm{H}_{2} \mathrm{O}$ by different ALD recipes before and after the Parafilm removal. The first sample was deposited at $175^{\circ} \mathrm{C}$ using a precursor pulse time of $0.2 \mathrm{~s}$ and a nitrogen purge time of $5 \mathrm{~s}$; the second sample was deposited at $100{ }^{\circ} \mathrm{C}$ using a precursor pulse time of $0.2 \mathrm{~s}$ and a nitrogen purge time of $5 \mathrm{~s}$; the third sample was deposited at $100{ }^{\circ} \mathrm{C}$ using a precursor pulse time of $0.2 \mathrm{~s}$ and a nitrogen purge time of $30 \mathrm{~s}$. (b) EDX measurement on the Parafilm, below the Parafilm and on the non-masked areas after the $\mathrm{TiO}_{2} \mathrm{ALD}$ process for the first sample deposited at $175^{\circ} \mathrm{C}$. (c) Film thickness as a function of the distance from the edge of the Parafilm protected area for the first sample deposited at $175^{\circ} \mathrm{C}$.

Iridium films were grown at $225^{\circ} \mathrm{C}$ in the $\mathrm{F} 120$ reactor. Two substrates were held in the reaction chamber vertically and opposite to each other with only $2 \mathrm{~mm}$ flow channel in between: the Parafilm masked Si and a bare Si substrate. Figure 4(a) presents images of the two substrates after the iridium ALD process. At this temperature, the Parafilm mask can protect the Si surface against ALD growth. Different from the oxide processes, EDX measurements [Fig. 4(b)] show that there was no iridium 
growth on both the Parafilm and the substrate underneath it. However, Fig. 4(a) demonstrates that there was also no iridium growth on the areas downstream from the Parafilm mask, which was confirmed by using EDX to measure the areas marked with the red circle in figure. As is well known, ALD processes of iridium and other noble metals are very sensitive to the substrate surface, and so, it is suggested that the volatile compounds (hydrocarbon molecules) coming out from the Parafilm during the ALD process adsorbed on the silicon surface, thus preventing iridium growth on these areas. Because of the cross-flow reactor design, with a narrow channel between the substrates, the outgassing compounds were efficiently transported by the carrier gas downstream and the areas upstream of the Parafilm were not affected. The uniformity of the iridium films next to the Parafilm mask was checked by EDX line scan of the Ir L $\alpha$ signal [Fig. 4(c)], along the blue arrow marked in the enlarged SEM image [Fig. 4(a)]. It was found that in the area $2 \mathrm{~mm}$ away from the starting point of the EDX line scan measurement, the Ir L $\alpha$ signal stabilizes to a level corresponding to a film thickness of $18 \mathrm{~nm}$ as calculated using the GMRFILM program. The film is a little thinner than the iridium film $(20 \mathrm{~nm})$ deposited with the same ALD recipe without the Parafilm mask on Si. Therefore it appears that the volatile compounds from Parafilm might slow down the growth process a little also on the growth areas. The dark area near the Parafilm in Fig. 4(a) shows no iridium peak in the EDX spectrum, and so, the iridium L $\alpha$ intensity in the EDX line scan in this area in Fig. 4(c) is the noise level. Because outgassing from the Parafilm affected the ALD film growth to various extents, a question arises whether it could also add impurities to the ALD films. This was checked by performing ToF-ERDA measurements on films deposited on the nonmasked areas for all three materials $\left(\mathrm{Al}_{2} \mathrm{O}_{3}, \mathrm{TiO}_{2}\right.$, and Ir). Only about $0.2-0.5$ at. \% increase of carbon impurity was observed, as compared with the reference samples deposited without Parafilm in the ALD process. 
a)

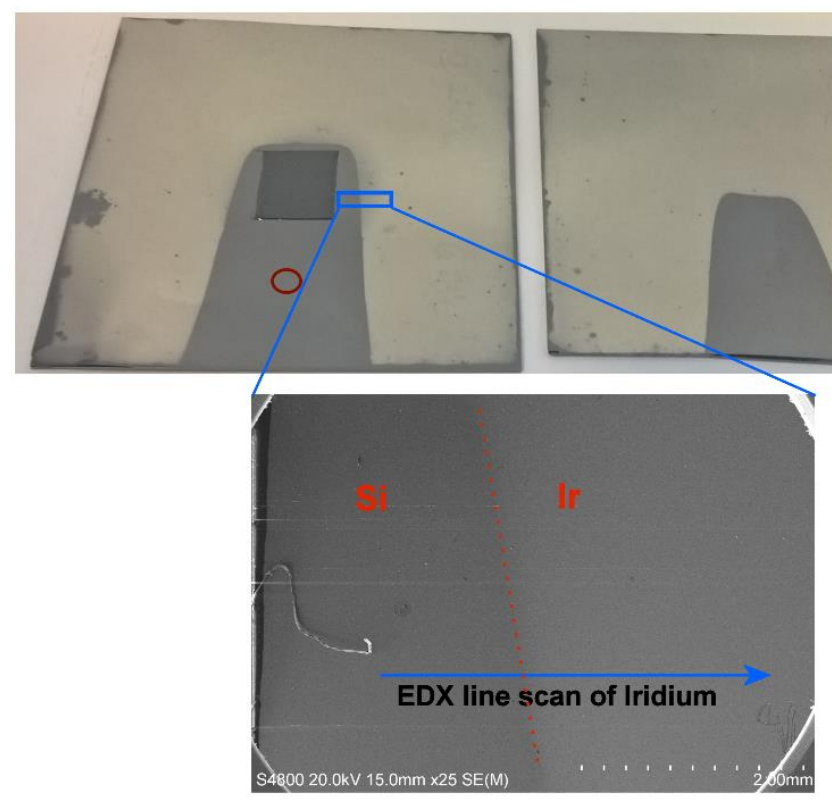

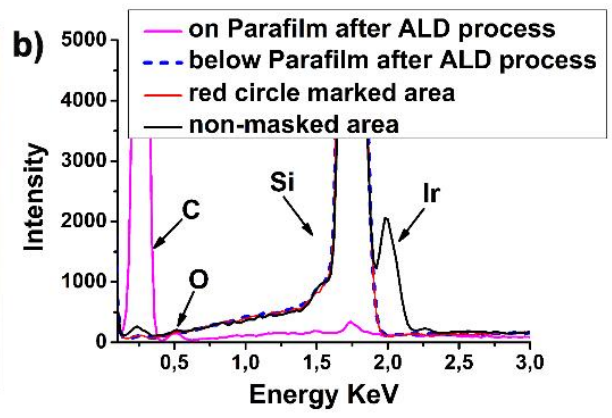

c)

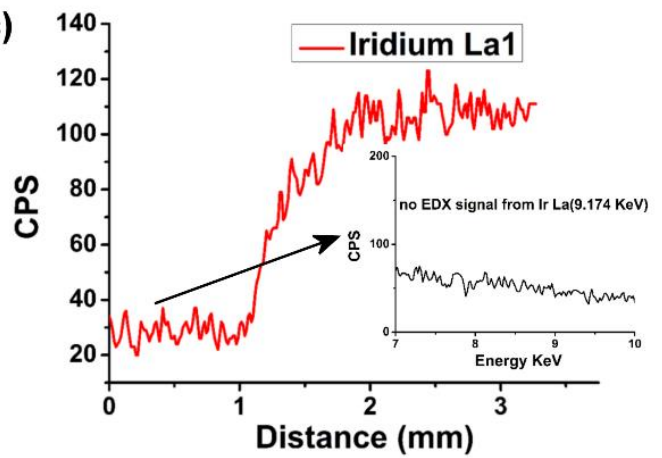

FIG. 4. (Color online) (a) Photographs of the $5 \times 5 \mathrm{~cm}$ substrates with patterned iridium films deposited from $\operatorname{Ir}(\mathrm{acac})_{3}$ and $\mathrm{O}_{2}$ at $225{ }^{\circ} \mathrm{C}$ before the Parafilm removal. The image at the bottom is an SEM image of the area indicated. (b) EDX measurements on the Parafilm, underneath the Parafilm, nonmasked areas and the red circle marked area after the iridium ALD process. (c) EDX line scan of iridium L $\alpha$ along the blue arrow.

\section{IV.SUMMARY AND CONCLUSIONS}

The use of Parafilm as a blocking mask is a simple, clean, and effective method for patterned ALD film growth on a large area scale. Its blocking ability was tested for ALD deposition of $\mathrm{Al}_{2} \mathrm{O}_{3}, \mathrm{TiO}_{2}$, and $\mathrm{Ir}$ in a temperature range of 100 to $300{ }^{\circ} \mathrm{C}$. Parafilm can protect the substrate against all these ALD processes but $\mathrm{Al}_{2} \mathrm{O}_{3}$ and $\mathrm{TiO}_{2}$ were found to grow also on top of the Parafilm. In the $\mathrm{Al}_{2} \mathrm{O}_{3}$ ALD process, the Parafilm works well up to $275{ }^{\circ} \mathrm{C}$, but it flows downward on a vertical substrate at $300{ }^{\circ} \mathrm{C}$. The outgassing of Parafilm at high deposition temperatures can slow down or even prevent ALD film growth on nonmasked areas around the mask, as noticed especially in the $\mathrm{TiO}_{2}$ and iridium growth. In the $\mathrm{Al}_{2} \mathrm{O}_{3}$ film growth, the outgassing has only a minor effect on the deposition, which can be accepted in ALD deposition for larger area scale patterning. This method has potential for blocking film growth behind 
the substrate and inhibiting detrimental growth on contact areas in IC and MEMS, especially for the processes which are robust enough not to be disturbed by outgassing.

\section{ACKNOWLEDGMENTS}

The financial support from the China Scholarship Council (File No. 201507040043) and the

Finnish Centre of Excellence in Atomic Layer Deposition (CoE in ALD) is gratefully acknowledged.

The authors gratefully acknowledge Kenichiro Mizohata for ToF-ERDA measurements, Marianna

Kemell for the teaching of EDX line scan measurements, and Peter King for revision of the manuscript.

$1 \quad$ M. Leskelä and M. Ritala, Angewandte Chemie International Edition 42, 5548 (2003).

2 M. Ritala, M. Leskelä, J. P. Dekker, C. Mutsaers, P. J. Soininen, and J. Skarp, Chemical Vapor Deposition 5, 7 (1999).

M. Leskelä and M. Ritala, Thin Solid Films 409, 138 (2002).

S. I. Association, National technology roadmap for semiconductors (SIA, 1997).

P. A. Packan, Science 285, 2079 (1999).

N. Pinna and M. Knez, Atomic layer deposition of nanostructured materials (John Wiley \& Sons, 2012).

M. Knez, K. Nielsch, and L. Niinistö, Advanced Materials 19, 3425 (2007).

J. P. Lee and M. M. Sung, J. Am. Chem. Soc. 126, 28 (2004).

A. Mackus, A. Bol, and W. Kessels, Nanoscale 6, 10941 (2014).

X. Jiang and S. F. Bent, The Journal of Physical Chemistry C 113, 17613 (2009).

R. Chen, H. Kim, P. C. Mclntyre, and S. F. Bent, Appl Phys Lett 84, 4017 (2004).

A. V. Walker, Langmuir 26, 13778 (2009).

L. Guo, X. Qin, and F. Zaera, ACS Applied Materials \& Interfaces 8, 6293 (2016).

L. Guo, I. Lee, and F. Zaera, ACS Applied Materials \& Interfaces 8, 19836 (2016).

F. S. Minaye Hashemi, C. Prasittichai, and S. F. Bent, ACS nano 9, 8710 (2015).

J. Huang, M. Lee, and J. Kim, Journal of Vacuum Science \& Technology A 30, 01 A128 (2012).

E. Farm, M. Kemell, M. Ritala, and M. Leskela, Thin Solid Films 517, 972 (2008).

E. Farm, S. Lindroos, M. Ritala, and M. Leskela, Chemistry of Materials 24, 275 (2012).

W. Lee, N. P. Dasgupta, O. Trejo, J.-R. Lee, J. Hwang, T. Usui, and F. B. Prinz, Langmuir 26, 6845 (2010).

R. H. A. Ras, E. Sahramo, J. Malm, J. Raula, and M. Karppinen, J. Am. Chem. Soc. 130, 11252 (2008).

E. Farm, M. Kemell, M. Ritala, and M. Leskela, J Phys Chem C 112, 15791 (2008).

E. Farm, M. Kemell, E. Santala, M. Ritala, and M. Leskela, J Electrochem Soc 157, K10 (2010).

A. Sinha, D. W. Hess, and C. L. Henderson, J Vac Sci Technol B 24, 2523 (2006).

H. J. V. René, S. Akhil, J. Yuqing, M. M. K. Wilhelmus, and A. B. Ageeth, Nanotechnology 27, 405302 (2016).

25 C. R. Ellinger and S. F. Nelson, Chemistry of Materials 26, 1514 (2014).

26 M. C. Langston, T. Usui, and F. B. Prinz, Journal of Vacuum Science \& Technology A 30, 01A153 (2012).

27 T. Aaltonen, M. Ritala, V. Sammelselg, and M. Leskelä, J Electrochem Soc 151, G489 (2004). 
R. Waldo, Microbeam Analysis Society, Milwaukee (1988).

29 R. Matero, A. Rahtu, M. Ritala, M. Leskelä, and T. Sajavaara, Thin Solid Films 368, 1 (2000). 